\title{
A importância da ecocardiografia contrastada no diagnóstico de DSV em equino: relato de caso
}

Beatriz Arruda Woserow, Raíssa Karolliny Salgueiro Cruz, Juliana Bornhausen Araújo, Amanda Sarita Cruz Aleixo, Karoline Koether, Maurício Gianfrancesco Filippi, Juliana Almeida Nogueira da Gama, Mayra de Castro Ferreira lima, Simone Biagio Chiacchio, Maria Lúcia Gomes Lourenço

Faculdade de Medicina Veterinária e Zootecnia, Universidade Estadual Paulista (UNESP), Botucatu, SP, Brasil

*Autor correspondente

e-mail: chiacchios@fmvz.unesp.br

\section{Resumo}

As anormalidades congênitas do sistema cardiovascular enquadram-se entre as mais frequentemente encontradas em animais domésticos, porém são raramente descritas em equinos. 0 defeito de septo ventricular (DSV) é a cardiopatia congênita mais comumente encontrada em equinos e caracteriza-se por uma abertura na porção do septo ventricular, que separa o ventrículo direito do esquerdo, geralmente atingindo a porção membranosa do septo, próximo da artéria aorta, promovendo comunicação livre do sangue entre os dois ventrículos. A ecocardiografia contrastada é uma técnica que utiliza agentes de contraste à base de microbolhas injetadas por via endovenosa periférica para melhorar o sinal ecocardiográfico. 0 objetivo do presente trabalho foi descrever o caso de um animal da espécie equina, portador de defeito de septo ventricular, e a utilização do teste de microbolhas com solução salina como auxílio na determinação da evolução da doença. Foi atendida uma potra, da raça Paint Horse, um ano de idade, $240 \mathrm{~kg}$. A queixa principal era de letargia há uma semana. Ao exame clínico, o animal apresentava-se em estação, mucosas róseas, hidratado, pulso forte e rítmico, temperatura retal de $38,2 \stackrel{\circ}{\circ}$, taquicardia ( 64 batimentos por minuto - bpm) e taquipnéia (48 movimentos por minuto - mpm). À auscultação cardíaca, verificou-se sopro holossistólico (grau V/VI), audível nos quatro focos, com ponto de maior intensidade no 5o espaço intercostal direito, foco tricúspide. À palpação torácica, detectou-se frêmito bilateral. Durante a auscultação pulmonar, notou-se aumento dos sons broncobronquiolares. Ao ecodopplercardiograma, verificou-se a presença de defeito de septo ventricular com extensão de 2,03 cm. Optou-se por realizar o teste de microbolhas em solução salina visando complementar o diagnóstico de VSD e acompanhamento da evolução para shunt reverso. 0 teste consistiu em cateterização da veia jugular direita e aplicação de contraste com microbolhas (produzidas por meio de pressão exercida sobre torneira de três vias, promovendo a transferência de $20 \mathrm{~mL}$ de solução salina e $0,4 \mathrm{ml}$ de ar), administradas rapidamente pelo acesso venoso periférico. 0 estudo foi considerado 
positivo, quando detectada a presença anormal de contraste em câmaras cardíacas esquerdas. O DSV é a malformação cardíaca congênita mais comum observada na espécie equina. Quando um DSV está presente, o padrão de fluxo habitual é a partir do ventrículo esquerdo para o direito, sendo que com a evolução da doença e a presença de hipertensão pulmonar ocorre reversão do shunt e consequente sobrecarga de volume em ambos os ventrículos. 0 teste de microbolhas é utilizado para auxiliar no diagnóstico da reversão do shunt no DSV. 0 aparecimento de contraste, ao corte longitudinal quatro câmaras, caracterizou-se pelo preenchimento completo inicial das cavidades direita (átrio e ventrículo) e posterior aparecimento das bolhas no ventrículo esquerdo. A técnica é bem fundamentada em cães e a importância desse relato é enfatizar que esta deve ser utilizada em animais de grande porte com objetivo semelhante, uma vez que é efetiva.

Palavras-chave: Anormalidade congênita. Equino. Sopro. Defeito. Coração. 